\title{
Immunohistochemical characterization of the "intimal proliferation' phenomenon in Sneddon's syndrome and essential thrombocythaemia
}

\author{
E.TAMM, W.JUNGKUNZ, ${ }^{*}$ M.WOLTER* AND W.CH.MARSCH† \\ Department of Anatomy, Friedrich-Alexander-Universität Erlangen-Nürnberg, Erlangen, Germany \\ *Department of Dermatology. Johann Wolfgang Goethe Universität Frankfurt am Main, Germany \\ †Department of Dermatology, Martin Luther Universität, Halle-Wittenberg, Germany \\ Accepted for publication 24 March 1994
}

Summary Cellular changes were immunocytochemically characterized in skin vessels of five patients with idiopathic generalized racemose livedo (Sneddon's syndrome), and one patient with localized racemose livedo associated with essential thrombocythaemia. Antibodies against $\alpha$-smooth muscle-actin, tropomyosin, desmin, vimentin, factor VIII-related antigen, human endothelial cells (CD31), human macrophages (CD68), and HLA-DR positive cells (CR3/43) were used. Conventional light microscopy showed, in all cases, intimal thickening of ascending arteries and arterioles as a result of an accumulation of cells and extracellular hyalinized material. None of the specimens showed infiltration with polymorphonuclear leucocytes or macrophages. The cells in the region of the intimal hyperplasia showed intense positive immunostaining for $\alpha$-smooth muscle actin and tropomyosin. Staining for the intermediate filament desmin was localized to the resident smooth muscle cells of the media, whereas staining for vimentin was found in all types of cells in both the intima and media. Positive immunostaining for factor VIII-related antigen and CD31 was strictly confined to the endothelial cells lining the narrowed lumina of the vessels. No positive staining with either antibody was observed in totally occluded vessels. Cells in the subintimal space did not show reactivity for CD68 in any of the specimens, but two cases showed solitary cells with positive staining for HLA-DR in this region. There were no differences in staining pattern between Sneddon's syndrome and essential thrombocythaemia with any of the antibodies. Our results support the assumption that the 'intimal proliferation' in both diseases is caused by colonization of the subendothelial space with contractile cells of possible smooth muscle origin. The similarities in histopathology and immunocytochemistry might indicate that in both diseases platelet-derived factors play a causative role.

Generalized racemose livedo (GRL), a widespread symmetrical, racemose livedo involving both the trunk and limbs, is a cutaneous arterio-occlusive disorder, which was first described in association with chronic infections such as syphilis and tuberculosis. ${ }^{1,2}$ Sneddon $^{3}$ characterized an association of idiopathic GRL with cerebrovascular defects, such as ischaemic strokes, an association which was subsequently confirmed, and found to occur in nearly $75 \%$ of cases. ${ }^{4-7}$ This neurocutaneous disorder has been accepted as a separate

Correspondence: Privatdozent Dr Ernst Tamm. Anatomisches Institut II. Universität Erlangen-Nürnberg, Universitätsstr. 19, D-91054 Erlangen, Germany.

This paper was presented in part at the XXth Annual Meeting of the Arbeitsgemeinschaft Dermatologische Forschung (ADF), 13-15 November 1992, Mainz, Germany. entity, and designated Sneddon's syndrome. It has been suggested from histological studies that the skin alterations are caused by 'intimal proliferation' in ascending arteries and arterioles in the upper subcutis and deep dermis. ${ }^{4,8-13}$ In a previous electron microscopic investigation, ${ }^{14}$ we observed an accumulation of cells, with the ultrastructural characteristics of vascular smooth muscle cells, in the subendothelial space of affected vessels. To further characterize these cells, skin biopsies from five patients with Sneddon's syndrome were investigated using immunohistochemical methods. The results were compared with those from a patient with localized racemose livedo (LRL; circumscribed livedo in one or two adjacent anatomical regions, most often asymmetrical) in association with essential thrombocythaemia. 


\section{Methods}

\section{Patients}

Case 1. A 27-year old woman with GRL for 7 years. Several months before the onset of GRL, the patient suffered from an ischaemic stroke. She was a smoker, took oral contraceptives containing oestradiol-derivatives, and had arterial hypertension.

Case 2. A 50-year-old woman with GRL for 4 years. After the onset of GRL, she suffered from several ischaemic strokes. She was a smoker, and had arterial hypertension.

Case 3. A 38-year-old woman with GRL for 5 years. One year before the onset of GRL, the patient had an ischaemic stroke. After the stroke, she suffered from grand mal attacks, and complained of blurred vision and vertigo. She had arterial hypertension and a history of intake of oral contraceptives.

Cases 4 and 5. Forty-nine and 51-year-old women, with GRL for 8 and 10 years, respectively. Both patients were heavy smokers. To date, neither has developed any neurological abnormalities.

Case 6. A 58-year-old woman with LRL for 3 months. The cutaneous abnormalities were localized to the heels, ankles, and lateral sides of both feet. The skin temperature in affected areas was raised. The patient suffered from a burning sensation of the palms and soles on exposure to warmth, consistent with a diagnosis of erythromelalgia (erythermalgia). Platelet counts were repeatedly above a level of $600 \times 10^{9} / \mathrm{l}$. The patient was a smoker, and suffered from arterial hypertension.

\section{Assessment}

Cases 1-5 were diagnosed as suffering from Sneddon's syndrome, and three had prior or concomitant cerebrovascular abnormalities. None of the patients had a positive VDRL test, autoantibodies, or rheumatoid factor, nor did they have a history of ulceration, bleeding, or other thrombotic episodes. Platelet counts in all cases were within the normal range (150$\left.450 \times 10^{9} / 1\right)$.

Case 6, with LRL, underwent further haematological investigations, leading to a diagnosis of essential thrombocythaemia, according to the criteria of Murphy et al. ${ }^{15}$

\section{Material}

Skin biopsies were obtained after intradermal injection of $1 \%$ lignocaine without adrenaline. Multiple punch biopsies $(4 \mathrm{~mm})$ were obtained, and processed for immunomicroscopy. According to the recommendations of Marsch and Muckelmann, ${ }^{14}$ the biopsies were taken from clinically normal-looking skin adjacent to the livid racemose streaks, and included the upper subcutis.

\section{Immunohistochemistry}

The skin biopsies were fixed in $4 \%$ buffered formaldehyde for $24 \mathrm{~h}$, and then embedded in paraffin. Fivemicrometre sections were cut, and were either stained by a trichrome stain, or further processed for immunohistochemistry. The sections were deparaffinized, and preincubated for $45 \mathrm{~min}$ with Blotto's dry milk solution. ${ }^{16}$ For demonstration of the intermediate filament desmin, a monoclonal antibody from Dakopatts (Hamburg, Germany) was used (clone D33, antihuman IgG1) at a dilution of $1: 50$. For vimentin, a monoclonal mouse antiporcine antibody from Dakopatts (clone $\mathrm{V} 9, \mathrm{IgG} 1)^{17}$ was applied to the sections at a dilution of $1: 5$. Demonstration of $\alpha$-smooth muscle (sm)-actin was performed using a monoclonal mouse antibody to smooth muscle specific $\alpha$-sm-actin (clone 1A4, IgG2a $^{18}$ (Sigma, St Louis, MO, U.S.A.). The antibody was diluted in PBS $(1: 150)$ with $1 \%$ bovine serum albumin (Sigma). Tropomyosin was visualized using a monoclonal mouse antibody against chicken gizzard tropomyosin (clone TM311, IgG1, Sigma) diluted $1: 100$. The demonstration of monocyte/macrophageassociated antigens was achieved using mouse antihuman macrophage CD68 antibodies (clone PG-M1, Dakopatts, diluted 1:50). ${ }^{19}$ Endothelial cells were stained with antibodies against human endothelial cell CD 31 (clone JC/70A, Dakopatts, $1: 50$ ), ${ }^{20}$ and against factor VIII-associated antigen (clone F8/86, Dakopatts, $1: 20$ ). The presence of cells expressing MHC class II antigens was investigated with a monoclonal mouse antibody from Dakopatts (clone CR3/43, $1: 50) .{ }^{21}$ After incubation with the primary antibody for $90 \mathrm{~min}$, the sections were either incubated with fluorescein-labelled rabbit antimouse IgG (Dakopatts), or processed for the alkaline phosphatase anti-alkaline phosphatase (APAAP) technique. For the APAAP technique, the sections were incubated with rabbit antimouse immunoglobulins (Dakopatts) at a dilution of $1: 25$, and then incubated with the APAAP complex 

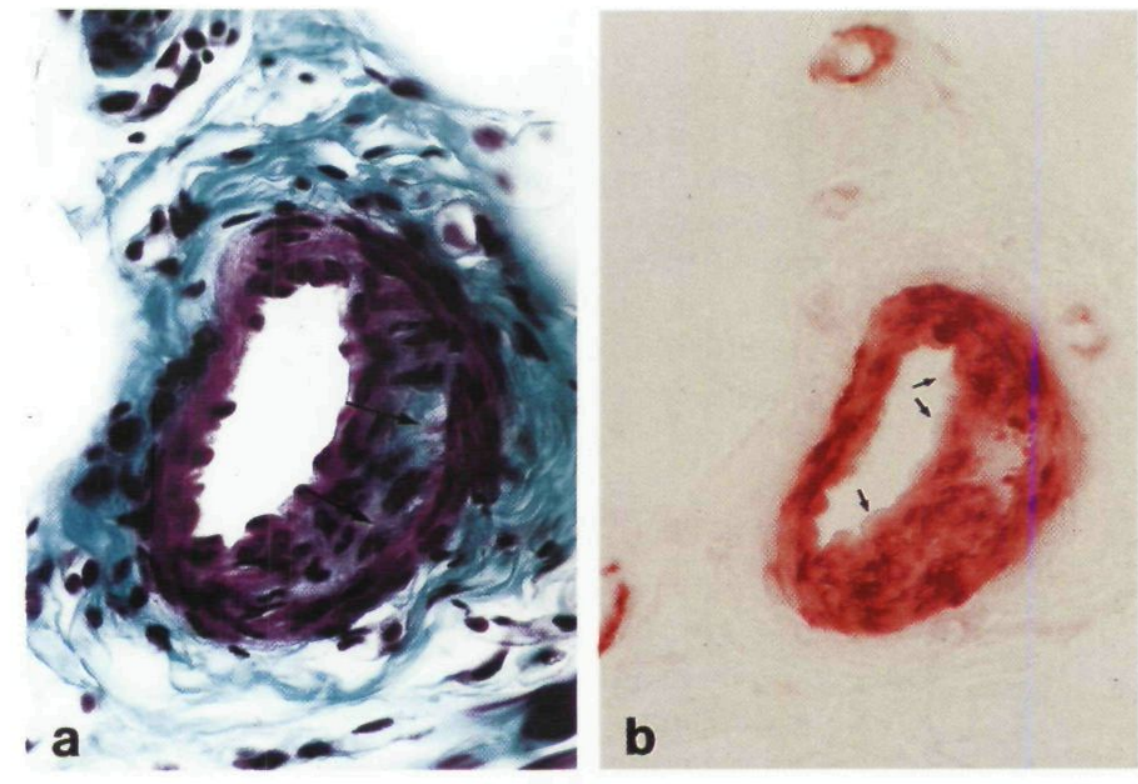

Figure 1. Partially occluded cutaneous arteriole in generalized racemose livedo. (a) The vessel is characterized by a narrowed lumen and crescent-like intimal proliferation (arrows). (b) Immunostaining of a consecutive section of the same vessel with antibodies against tropomyosin (APAAP). Resident smooth muscle cells and cells of the intimal proliferation are positively labelled. In contrast, the endothelial cells are not stained (arrows) $(\times 400)$.
(1:1000, Dakopatts). Visualization of alkaline phosphatase was achieved with new fuchsin as substrate. The sections were mounted in Entellan (Merck, Darmstadt, Germany), and viewed with a Leitz Aristoplan microscope (Leitz, Wetzlar, Germany).

\section{Results}

Conventional light microscopy confirmed intimal thickening of ascending small- to medium-sized arteries at the dermis-subcutis border in all six cases. No changes were observed in the upper dermis. In addition to arteries, larger arterioles, with an ill-defined lamina elastica interna and a media two to three smooth muscle cells in thickness were affected. The intimal thickening was caused by an accumulation of both cells and extracellular hyalinized material. Partially occluded vessels, which were characterized by a narrowed lumen and a crescent-like intimal proliferation, were present in all cases (Fig. 1). In three of the cases $(2,4,6)$, vessels with a totally occluded lumen were observed (Figs 2, 4 and 5). Some of the occluded vessels contained small capillary lumina, indicating recanalization (Fig. 3). No platelet aggregates were seen in any of the affected vessels.

In all affected vessels, both the resident vascular
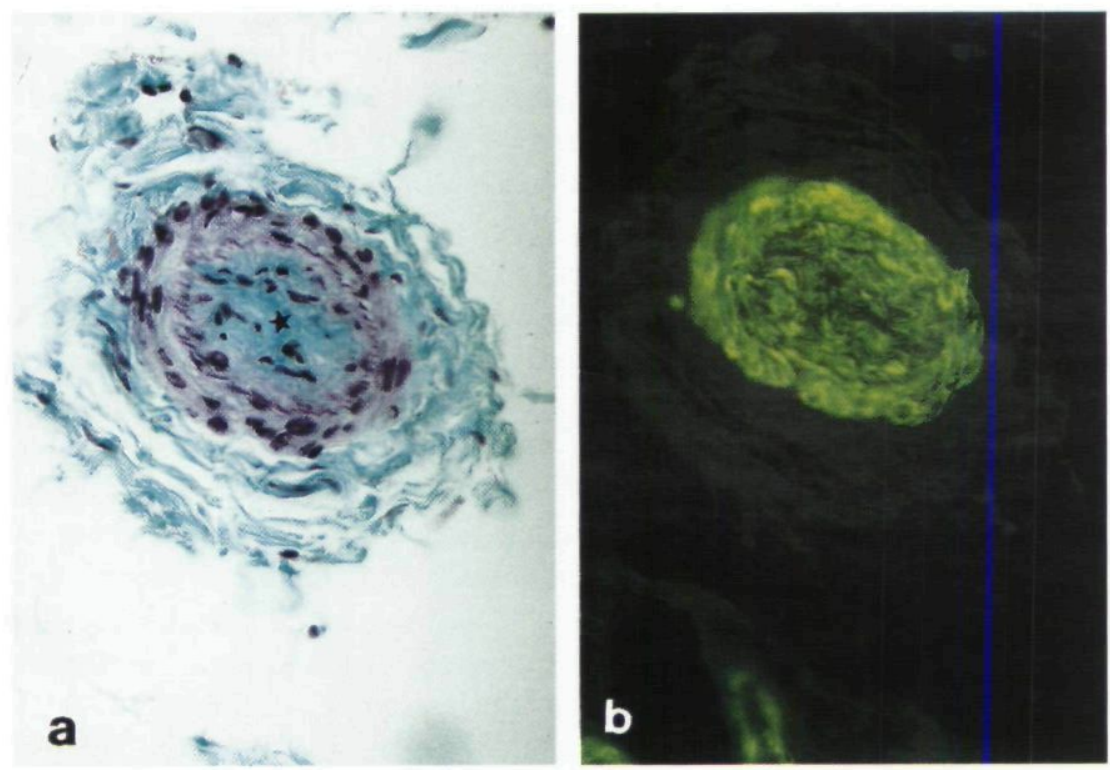

Figure 2. (a) Completely occluded arteriole at the subcutis-dermis border in a patient with generalized racemose livedo. The intima shows an accumulation of cells and large amounts of extracellular hyalinized material (asterisk). (b) Consecutive section of the same vessel after staining for $\alpha$-smactin. The resident muscle cells of the tunica media and the cells in the intimal proliferation show intense positive immunofluorescence $(\times 400)$. 


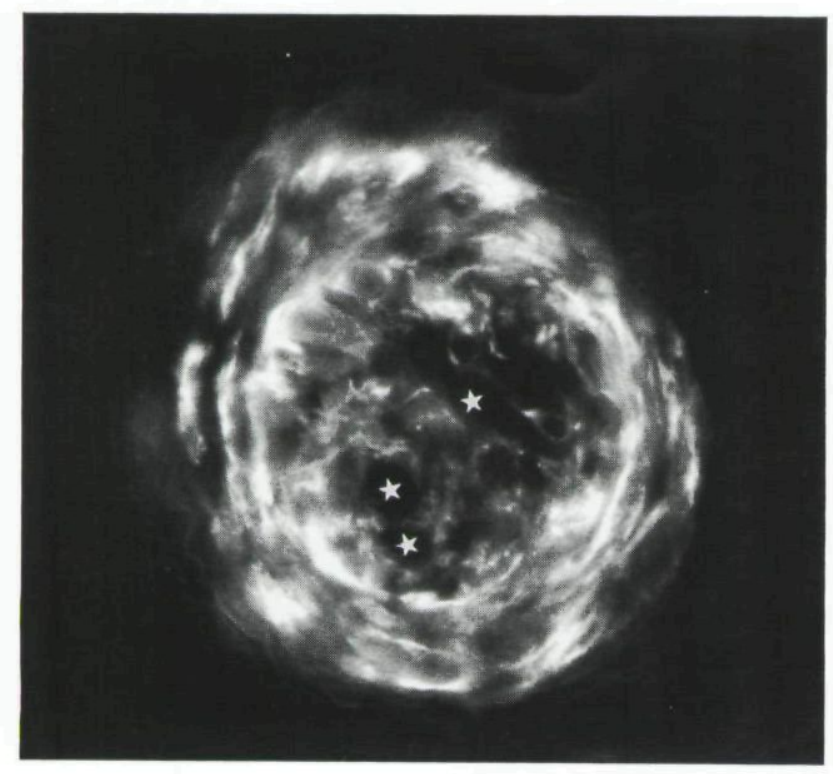

Figure 3. Occluded cutaneous arteriole in generalized racemose livedo after immunostaining for $\alpha$-sm-actin $(\times 400)$. The vessel contains small capillary lumina, indicating recanalization (asterisks). Resident smooth muscle cells and cells in the intimal proliferation show positive immunofluorescence for $\alpha$-sm-actin.

smooth muscle cells, outside the elastica interna, as well as all cells within the subintimal thickening, showed positive immunoreactivity for $\alpha$-sm-actin (Figs $2 \mathrm{~b}$ and 3). The staining pattern for tropomyosin was identical to that of $\alpha$-sm-actin (Fig. 1b). Neither antibody stained endothelial cells. Positive staining for the intermediate filament desmin was observed in the media of arteries and arterioles (Fig. 4b), where most of the resident smooth muscle cells were stained. Desmin staining was very weak in the cells of the intimal proliferation. In contrast, staining for vimentin was found in all types of cells in both intima and media (Fig. 4c). Positive immunoreactivity for factor VIII-related antigen and CD 31 was strictly confined to the endothelial cells lining the narrowed lumen of the vessel (Fig. 5a). No positive staining with either antibody was observed in totally occluded vessels. There was no reactivity for CD68 in cells in the region of intimal proliferation in any of the specimens (Fig. 5 b). In two cases (1 and 3), solitary cells in the intimal space stained with antibodies against HLA-DR. In all cases, several scattered macrophages in the perivascular connective tissue were positively labelled for CD68 and HLA-DR (Fig. 5b and c). Compared with normal skin, there was no increase of such cells in the perivascular area. None of the specimens showed infiltration with polymorphonuclear leucocytes or macrophages.
There was no difference in staining pattern between GRL and LRL with thrombocythaemia with any of the antibodies.

\section{Discussion}

In the present study, all cases of Sneddon's syndrome showed intimal proliferation in arteries at the dermissubcutis border, corroborating previous findings. ${ }^{4,9-13}$ In contrast with the observations of Zelger et al., ${ }^{13}$ vessels with a poorly defined elastica interna and a media two to three muscle cells thick, which we regarded as arterioles, in accordance with standard definitions, ${ }^{22}$ were also affected. Our results further underline our previous assumption, based on electron microscopic observations, that the occlusive arteriolopathy in Sneddon's syndrome is caused by a colonization of the subendothelial space with contractile cells of smooth muscle origin. ${ }^{14}$ In all affected vessels, the cells in the region of the intimal proliferation stained positive with antibodies against typical smooth muscle proteins such as tropomyosin and $\alpha$-sm-actin. Antibodies against the $\alpha$-sm-actin isoform ${ }^{23}$ have been shown to specifically stain smooth muscle cells of different origins as well as myofibroblasts. ${ }^{18,24-28}$ The $\alpha$-actin positive cells in the subendothelial space of diseased vessels in Sneddon's syndrome are most probably derived from muscle cells in the tunica media, as myocytes migrating through the gaps in the elastica interna have been observed ultrastructurally in these lesions. ${ }^{14}$ In addition, the cells of the intimal proliferation stained intensely for the cytoskeletal element vimentin, which is in accordance with the ultrastructural observation of numerous $7-8 \mathrm{~nm}$ intermediate filaments in these cells. ${ }^{14}$ In contrast, desmin positive cells were observed in resident smooth muscle cells of the tunica media, but were very sparse in the subendothelial lesions. Similar findings have been reported for proliferating human arterial smooth muscles cells in fibrous atheromatous plaques. ${ }^{29}$

Arterial hypertension and heavy smoking, both of which are factors that contribute to atherosclerosis, are commonly associated with Sneddon's syndrome, and were present in all our investigated cases. However, in contrast with the intimal thickening which occurs in atherosclerosis, ${ }^{30}$ the affected vessels in our patients did not show atherosclerotic plaques or accumulations of macrophages. In addition to histology, immunocytochemistry indicated that macrophages were very sparse in the intimal proliferation associated with Sneddon's syndrome. In addition to atherosclerosis, arterial hyper- 

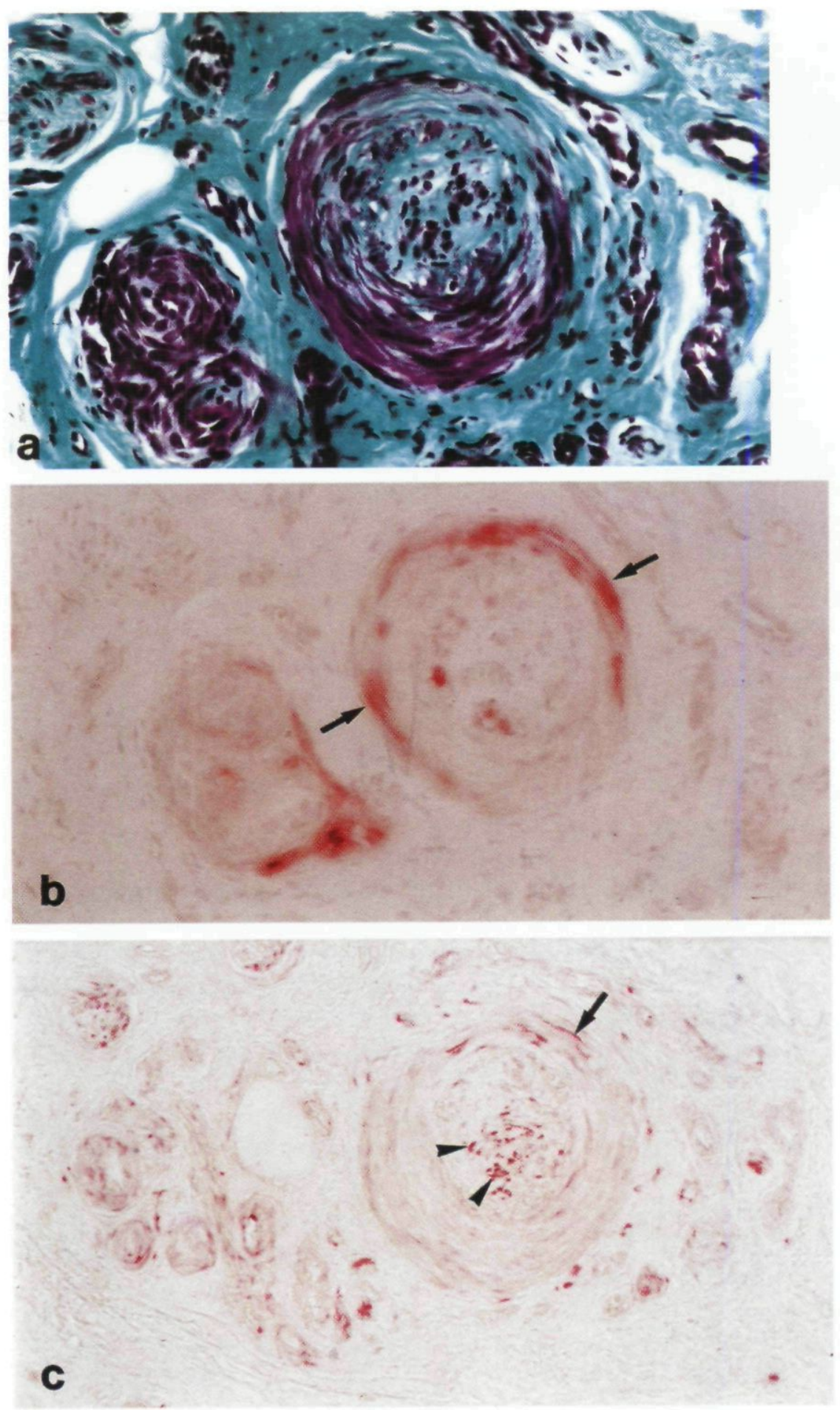

Figure 4. Occluded cutaneous arteriole in a patient with localized racemose livedo associated with thrombocythaemia $(\times 200)$. (a) Arterial vessels at the subcutis-dermis border show signs of intimal proliferation similar to those in generalized racemose livedo. (b) Consecutive section

immunostained for desmin. Most of the resident smooth muscle cells in the tunica media are positively stained (arrows). In contrast, there is almost no staining in the region of the intimal proliferation.

(c) Consecutive section after staining for vimentin. Cells in the intimal proliferation are intensely labelled (arrowheads). In addition, the resident smooth muscle cells are positively immunostained (arrow).

Figure 5. Totally occluded arterial vessel of a patient with generalized racemose livedo. (a) Staining for CD31 is strictly confined to endothelial cells (arrows). There is no staining in the totally occluded lumen (asterisk; $\times 200$ ). (b) Antibodies against CD68 label some scattered macrophages in the perivascular connective tissue (arrows). There is no labelling in the region of tunica media or intima $(\times 200)$. (c) Antibodies against HLA-DR stain perivascular macrophages and occasional solitary cells in the proliferating intima of the occluded vessels (arrows; $\times 400)$. 


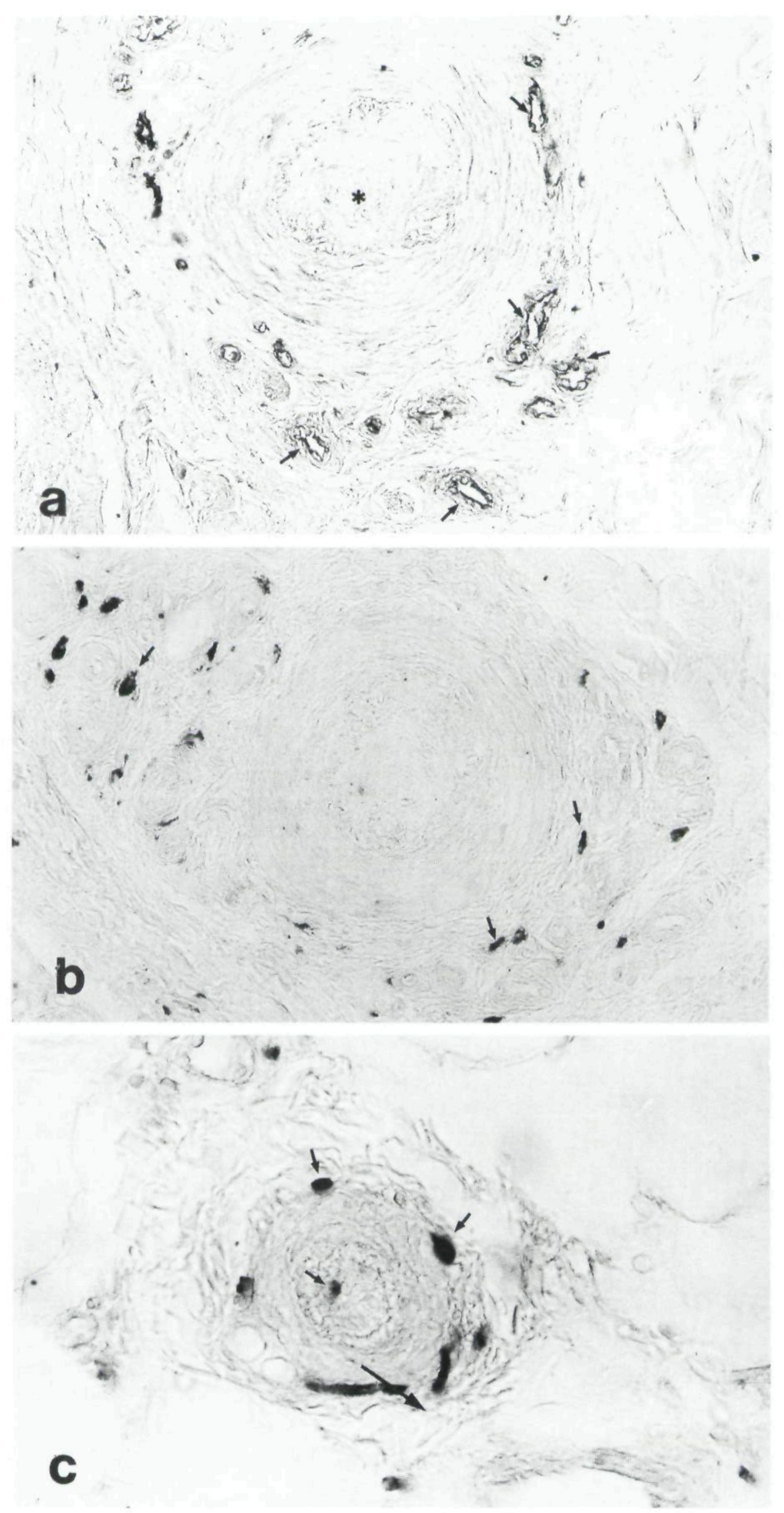


tension may also contribute to hyaline arteriolosclerosis in many organs, including kidney, pancreas, brain, and retina. This process includes necrosis of smooth muscle cells and replacement of the media by an accumulation of amorphous hyaline material, ${ }^{31,32}$ Again, such vascular changes were not observed in our study. We therefore consider that the vascular alterations observed in our patients are a characteristic part of the pathogenic process of Sneddon's syndrome, and are not induced by arterial hypertension or heavy smoking per se. In marked contrast with the findings of Zelger $e t$ al., ${ }^{13}$ we did not see vessels with adherent monocytes, a lymphohistiocytic infiltrate, or a sponge-like plug formed by mononuclear cells, fibrin and red blood cells. Such changes might be characteristic of initial lesions only. In our study, neither the laboratory results nor the clinical features suggested a diagnosis of the antiphospholipid syndrome, ${ }^{33}$ which is characterized by ulcerative haemorrhagic skin lesions due to intravascular thrombosis. ${ }^{34}$

Essential thrombocythaemia is known to occur in association with localized livedo, predominantly on the soles and lateral aspects of the feet. ${ }^{35-37}$ In our study, the cutaneous vascular lesions in thrombocythaemia were immunocytochemically indistinguishable from those of the patients with Sneddon's syndrome. This is in agreement with the findings of Michiels et al., ${ }^{38}$ who also observed narrowing of the vascular lumina caused by proliferation of smooth muscle cells in the cutaneous lesions of patients with essential thrombocythaemia. It has been suggested that intimal proliferation in essential thrombocythaemia is caused by increased amounts of cytokines or growth factors released by platelets. ${ }^{38}$ Indeed, platelet-derived growth factor is one of the most potent growth stimulating factors for vascular smooth muscle cells. ${ }^{30,39}$ It is of interest that haemostatic abnormalities have been reported in Sneddon's syndrome, especially hyperreactivity of platelets. ${ }^{40}$ It is not known whether platelet-derived factors may also account for the intimal proliferation in Sneddon's syndrome, but given the histopathological and immunocytochemical similarities between this entity and LRL associated with essential thrombocythaemia, it is distinctly possible.

\section{Acknowledgments}

We would like to thank Angelika Hauser and Ursi Bechmann for their expert help with the immunohistochemistry, and Marco Gößwein for his excellent technical expertise in preparation of the photomicrographs. The study was supported by a grant from the Johannes and Frieda Marohn-Stiftung, Erlangen, Germany.

\section{References}

1 Ehrmann S. Ein neues Gefäßsymptom bei Lues. Wien Med Wochenschr 1907; 57: 777-82.

2 Wertheim L. Livedo racemosa (Ehrmann) und livedo reticularis (annularis, lenticularis) perstans (Adamson). In: Handbuch der Haut- und Geschlechtskrankheiten. 12. Band, 2. Teil. Hämangiome (Jadassohn J, ed). Berlin: Springer-Verlag, 1932; 440-68.

3 Sneddon IB. Cerebro-vascular lesions and livedo reticularis. $\mathrm{Br} J$ Dermatol 1965; 77: 180-5.

4 Stamm T, Schmidt RC, Lubach D. Livedo racemosa generalisata (Ehrmann). Neurologische, neuroradiologische und histologische Beobachtungen. Nervenarzt 1982; 53: 211-18 (Ger.).

5 Lubach D, Stamm T. Generalized racemose livedo and neurological lesions. Br J Dermatol 1983; 108: 501.

6 Lubach D, Schwabe C, Weissenborn $\mathrm{K}$ et al. Livedo racemosa generalisata: an evaluation of thirty-four cases. I Am Acad Dermatol 1990; 22: 633-9.

7 Zelger B, Sepp N, Stockhammer G et al. Sneddon's syndrome. A long-term follow-up of 21 patients. Arch Dermatol 1993; 129: 437-47.

8 Ehrmann S. Weitere Mitteilungen über syphilitische Veränderungen der Hautgefäße und die damit zusammenhängenden Phänomene. Arch Dermatol Syphilol 1912; 113: 261-8.

9 Herzberg JJ. Livedo reticularis idiopathica and symptomatica. Ein Beitrag zur Pathologie der Arteriolen. Dermatol Wochenschr 1956; 134: 1045-53.

10 Röckl H, Metz J. Symptom: Livedo. In: Fortschritte der praktischen Dermatologie und Venerologie, Vol. 9 (Braun-Falco O, Wolff HH, eds). Berlin: Springer-Verlag, 1979; 163-70.

11 de Reus R, de Reuck J, Vermander F et al. Livedo racemosa generalisata and stroke. Clin Neurol Neurosurg 1985; 87: 143-8.

12 Bruyn RPM, van der Veen JPW, Donker AJM et al. Sneddon's syndrome. Case report and literature review. I Neurol Sci 1987; 79: 243-53.

13 Zelger B, Sepp N, Schmid KW et al. Life history of cutaneous vascular lesions in Sneddon's syndrome. Hum Pathol 1992; 23: 668-75.

14 Marsch WC, Muckelmann R. Generalized racemose livedo with cerebrovascular lesions (Sneddon syndrome): an occlusive arteriolopathy due to proliferation and migration of medial smooth muscle cells. Br J Dermatol 1985; 112: 703-8.

15 Murphy S, Iland H, Rosenthal D, Laszlo J. Essential thrombocythemia: an interim report of the Polycythemia Vera Study Group. Semin Hematol 1986; 23: 177-82.

16 Duhamel RC, Johnson DA. Use of nonfat dry milk to block nonspecific nuclear and membrane staining by avidin conjugates. J Histochem Cytochem 1985; 33: 711-14.

17 Osborn M, Debus E, Weber K. Monoclonal antibodies specific for vimentin. Eur J Cell Biol 1984; 34: 137-43.

18 Skalli O, Ropraz P, Trzeciak A et al. A monoclonal antibody against $\alpha$-smooth muscle actin: a new probe for smooth muscle differentiation. J Cell Biol 1986; 103: 2787-96.

19 Pulford KAF, Rigney EM, Micklem KJ et al. KP1: a new monoclonal antibody that detects a monocyte/macrophage associated antigen in routinely processed tissue sections. J Clin Pathol 1989: 42: 41421.

20 Parums DV, Cordell JL, Micklem K et al. JC70: a new monoclonal antibody that detects vascular endothelium associated antigen on routinely processed tissue sections. J Clin Pathol 1990; 43: 752-7. 
21 Steel CM. Disease Markers: Human Class II Antigens: Genetics. Structure and Function. Chichester: John Wiley \& Sons, 1984.

22 Titus JL, Kim H-S. Blood vessels and lymphatics. In: Anderson's Pathology (Kissane JM, ed), 9th edn. St Louis: The CV Mosby Company, 1989: 752-66.

23 Vandekerckhove J, Weber K. The complete amino acid sequence of actins from bovine aorta, bovine heart, bovine fast skeletal muscle and rabbit slow skeletal muscle. Differentiation 1979; 14: 121-33.

24 Skalli O, Vandekerckhove J, Gabbiani G. Actin-isoform pattern as a marker of normal or pathological smooth-muscle and fibroblastic tissues. Differentiation 1987; 33: 232-8.

25 Ramadori G, Veit T, Schwögler S et al. Expression of the gene of the $\alpha$-smooth muscle-actin isoform in rat liver and in rat fat-storing (ITO) cells. Virchows Arch [B] Cell Pathol 1990; 59: 349-57.

26 Czernobilsky B, Shezen E, Lifschitz-Mercer B et al. Alpha smooth muscle actin ( $\alpha$-SM actin) in normal human ovaries, in ovarian stromal hyperplasia and in ovarian neoplasms. Virchows Arch [B] Cell Pathol 1989; 57: 55-61.

27 Darby I, Skalli O, Gabbiani G. $\alpha$-smooth muscle actin is transiently expressed by myofibroblasts during experimental wound healing. Lab Invest 1990; 63: 21-9.

28 Tamm E, Flügel C, Stefani FH, Rohen JW. Contractile cells in the human scleral spur. Exp Eye Res 1992; 54: 531-43.

29 Kocher O, Gabbiani G. Cytoskeletal features of normal and atheromatous human arterial smooth muscle cells. Hum Pathol 1986; 17: 875-80.

30 Ross R. The pathogenesis of atherosclerosis: a perspective for the 1990s. Nature 1993; 362: 801-9.
31 Gamble CN. The pathogenesis of hyaline arteriolosclerosis. Am J Pathol 1986; 122: 410-20.

32 Garner A, Ashton N. Tripathi R et al. Pathogenesis of hypertensive retinopathy. An experimental study in the monkey. $\mathrm{Br} J$ Ophthalmol 1975; 59: 3-44.

33 Stephens CJM. The antiphospholipid syndrome. Clinical correlations, cutaneous features, mechanism of thrombosis and treatment of patients with the lupus anticoagulant and anticardiolipin antibodies. Br J Dermatol 1991; 125: 199-210.

34 Smith KJ, Skelton HG III, James WD et al. Cutaneous histopathologic findings in 'antiphospholipid syndrome'. Correlation with disease, including human immunodeficiency virus disease. Arch Dermatol 1990; 126: 1176-83.

35 Champion RH, Rook A. Idiopathic thrombocythemia. Cutaneous manifestations. Arch Dermatol 1963: 87: 302-5.

36 Michiels JJ, Abels J. Steketee J et al. Erythromelalgia caused by platelet-mediated arteriolar inflammation and thrombosis in thrombocythemia. Ann Intern Med 1985; 102: 466-71.

37 Schmutz JL, Cuny JF, Thess F et al. Livedo révélateur d'une thrombocytémie. Ann Dermatol Venereol 1987; 114: 227-31 (Fre.).

38 Michiels JJ, ten Kate FWJ, Vuzevski VD, Abels J. Histopathology of erythromelalgia in thrombocythaemia. Histopathology 1984; 8: 669-78.

39 Raines EW, Bowen-Pope DF, Ross R. Platelet-derived growth factor. In: Handbook of Experimental Pharmacology: Peptide Growth Factors and their Receptors (Sporn MB, Roberts AB, eds). Berlin: Springer-Verlag, 1990; 173-362.

40 Mayou SC, Ridler C, Kirby JD. Haemostatic abnormalities in Sneddon's syndrome. Br J Dermatol 1990; 123 (Suppl. 37): 35. 
This document is a scanned copy of a printed document. No warranty is given about the accuracy of the copy. Users should refer to the original published version of the material. 